\title{
Efficacy of low-dose lansoprazole in the treatment of non-erosive gastroesophageal reflux disease. Influence of infection by Helicobacter pylori
}

\author{
M. Castro Fernández, E. García Díaz, J. L. Larraona, M. C. Rodríguez Hornillo, E. Lamas Rojas, \\ D. Núñez Hospital and M. Pallarés Querol
}

Department of Gastroenterology. Hospital Universitario de Valme. Seville, Spain

\begin{abstract}
Introduction: proton pump inhibitors (PPIs) are the most effective drugs to cure peptic esophagitis and control the symptoms of gastroesophageal reflux disease (GERD). In most patients with GERD esophagitis is not detected by endoscopy, which represents GERD with a negative endoscopy or non-erosive reflux disease (NERD). The influence of infection by $H$. pylori in the evolution of GERD is controversial since a protective action is identified by some studies, but not all. We conducted a clinical trial to assess the efficacy of lansoprazole $15 \mathrm{mg} /$ day in the initial control of NERD symptoms, and as a secondary endpoint the impact of $H$. pylori infection on response to treatment.

Patients and methods: a pilot, single-center clinical trial was conducted -single-blind regarding the experimental medication (unknown to patients), and double-blind regarding the information concerning $H$. pylori infection. Sixty (60) patients with NERD were initially included, who had suffered from daytime or nocturnal heartburn for 1-2 days in each of the last two weeks. Nine patients were excluded for failing to comply with the study protocol. The 51 remaining patients, 35 women and 16 men, with a mean age of 49 years, comprised the per protocol analysis population. Patients received treatment for two weeks with a capsule of the study medication (15 mg/day of lansoprazole), with daily controls on the presence and severity of daytime and nocturnal heartburn. Treatment was considered effective when, upon completion, patients referred a maximum of one episode of mild heartburn as defined in the protocol, or answered the following question in the affirmative: "Does the medication you are receiving satisfactorily control the symptoms of your disease?".

During diagnostic endoscopy we obtained biopsies of the gastric body and antrum to investigate infection by $H$. pylori by means of a urease test. Treatment efficacy was assessed with no patients or doctors responsible for the study being aware of urease test results.
\end{abstract}

Results: 41 patients (80.3\%) reported that treatment had satisfactorily controlled their symptoms, and 34 patients (66.6\%) had

Recibido: 18-05-05.

Aceptado: 02-11-05.

Correspondencia: Manuel Castro Fernández. Área de Gastroenterología (Digestivo). Hospital Universitario de Valme (9 ${ }^{a}$ planta izda.). Ctra. de Cádiz, s/n. 41014 Sevilla. e-mail: mcastrof@meditex.es a maximum of one episode of mild heartburn in the last week. Forty-two (42) patients (82.3\%) had infection by $H$. pylori. No significant differences were observed in the response to treatment between patients with or without $H$. pylori infection.

Conclusions: with the limitations of a pilot study, these results suggest that lansoprazole $15 \mathrm{mg} /$ day is an effective treatment in the control of NERD symptoms, that it may be a good initial therapeutic strategy, and that, according to data available, $H$. pylori infection has no significant effect on the response to treatment.

Key words: Lansoprazole. Non-erosive reflux disease. Helicobacter pylori.

Castro Fernández M, García Díaz E, Larraona JL, Rodríguez Hornillo MC, Lamas Rojas E, Pallarés Querol M. Efficacy of low-dose lansoprazole in the treatment of non-erosive gastroesophageal reflux disease. Influence of infection by Helicobacter pylori. Rev Esp Enferm Dig 2006; 98: 170-179.

\section{INTRODUCTION}

Gastroesophageal reflux disease (GERD) is a highly prevalent (10-20\% of population) condition that may have a significant impact on quality of life and lead to a high use of healthcare resources. The etiopathogenesis of this disease is multifactorial, and the main factor responsible for it is a dysfunction of the lower esophageal sphincter (1-4).

In GERD there is a poor correlation between symptom severity (heartburn, acid regurgitations) and the presence of esophagitis. Approximately $65 \%$ of patients have nonerosive GERD (NERD), and 35\% have erosive esophagitis (5-7). 
Proton pump inhibitors (PPIs) are the most effective drugs to control GERD symptoms, and to endoscopically cure esophagitis $(8,9)$.

The efficacy of PPIs, and specifically of lansoprazole, is superior to that of $\mathrm{H} 2$-antagonists and, on the other hand, lansoprazole $30 \mathrm{mg} /$ day is more effective than lansoprazole $15 \mathrm{mg} /$ day in the curing of GERD with esophagitis (10-12). However, both these doses have similar efficacy as maintenance treatment for preventing a esophagitis relapse $(13,14)$. The efficacy of PPIs is greater in the population with GERD and esophagitis versus those with NERD. Ritcher et al. observed that lansoprazole $15 \mathrm{mg} /$ day is no less effective than lansoprazole $30 \mathrm{mg} /$ day in the treatment of NERD, with both doses being more effective than placebo or ranitidine $300 \mathrm{mg} /$ day $(15,16)$.

The influence of infection by Helicobacter pylori $(H$. pylori) on GERD's outcome and response to treatment is controversial. According to some studies, it has a protective effect decreasing the severity of symptoms or the prevalence of esophagitis, while other claim otherwise (17-33)

In this study we assessed, as our primary endpoint, the efficacy of lansoprazole at lower-than-conventional doses in the control of NERD, an increasingly prevalent condition with a growing impact on healthcare expenditure, and as our secondary endpoint the possible influence of $H$. pylori infection on response to treatment.

\section{MATERIAL AND METHODS}

\section{Study protocol}

We conducted a pilot, single-center clinical trial -single-blind with regards to the experimental medication (lansoprazole $15 \mathrm{mg} /$ day), unknown to patients, and double-blind with regards to $H$. pylori infection, which could be the basis for more comprehensive studies. We included 60 consecutive patients clinically diagnosed with GERD who complied with inclusion and exclusion criteria as shown in table I. During endoscopy we investigated $H$. pylori infection by means of a urease test on biopsies of the gastric body and antrum (Jatrox-Test). Infection by $H$. pylori was considered to be present when the urease test was positive for one or both locations within 24 hours. Patients provided their informed consent in writing, and were allowed to voluntarily withdraw from the study. The study was approved by the hospital's Ethic and Research Committees. A description of the study population, including demographic and clinical data, is shown in table II.

The capsules of the study medication, lansoprazole $15 \mathrm{mg}$, were to be taken once a day, 20-30 minutes before breakfast. During this treatment, the use of other PPIs, H2-antagonists, antibiotics, or drugs that could alter gastroesophageal reflux extent, induce dyspepsia, or interfere with the metabolism of lansoprazole was not permitted.
Table I. Inclusion and exclusion criteria

\begin{tabular}{|c|c|}
\hline Inclusion criteria & Exclusion criteria \\
\hline $\begin{array}{l}\text { Age }>18 \text { years } \\
\text { Non-erosive GERD }\end{array}$ & $\begin{array}{l}\text { Pregnant or breastfeeding women or } \\
\text { women of childbearing age without } \\
\text { effective contraception }\end{array}$ \\
\hline $\begin{array}{l}\text { Two or more heartburn episodes } \\
\text { per week }\end{array}$ & History of allergy to lansoprazole \\
\hline $\begin{array}{l}\text { Study of infection by } H \text {. pylori by urease } \\
\text { test on gastric body and antrum }\end{array}$ & $\begin{array}{l}\text { History of esophagitis, gastroduodenal } \\
\text { ulcer or digestive surgery }\end{array}$ \\
\hline $\begin{array}{l}\text { Absence of relevant gastric or } \\
\text { duodenal disease }\end{array}$ & $\begin{array}{l}\text { Liver or kidney impairment } \\
\text { Treatment in the } 4 \text { previous weeks } \\
\text { with anti-secretory agents (PPIs and } \\
\text { H2-antagonists) or antibiotics }\end{array}$ \\
\hline $\begin{array}{l}\text { Ability to correctly follow the study } \\
\text { instructions } \\
\text { Informed consent in writing }\end{array}$ & $\begin{array}{l}\text { Treatment in the } 2 \text { previous weeks } \\
\text { with NSAIDs and drugs able to alter } \\
\text { GER extent: theophylline, prokinetic } \\
\text { drugs, calcium antagonists, } \\
\text { beta-adrenergic agonists, meperidine } \\
\text { diazepam, antidepressants, anticholi } \\
\text { nergic drugs, etc.) }\end{array}$ \\
\hline
\end{tabular}

NSAIDs: non-steroidal anti-inflammatory drugs. PPIs: proton pump inhibitors Anti-H2: histamine $\mathrm{H} 2$ receptor antagonists. GER: gastroesophageal reflux.

Table II. Demographic and clinical data of the study populations

\begin{tabular}{|c|c|c|}
\hline & $\begin{array}{l}\text { ITT population } \\
\text { (No. } 57 \text { ) }\end{array}$ & $\begin{array}{l}\text { PP population } \\
\text { (No. 51) }\end{array}$ \\
\hline Mean age & 49.29 years & 49.12 years \\
\hline Mean weight & $74.51 \mathrm{k}$ & $73.95 k$ \\
\hline Mean height & $163 \mathrm{~cm}$ & $162 \mathrm{~cm}$ \\
\hline Men & $16(28 \%)$ & $16(31.4 \%)$ \\
\hline Women & $41(72 \%)$ & $35(68.6 \%)$ \\
\hline Mean time with GERD & 7.08 years & 6.93 years \\
\hline $\begin{array}{l}\text { Mean days of daytime heartburn } \\
\text { ( } 2 \text { previous weeks) }\end{array}$ & 10 days & 9.8 days \\
\hline $\begin{array}{l}\text { Severity of daytime heartburn: } \\
\text { Absent } \\
\text { Mild } \\
\text { Moderate } \\
\text { Severe }\end{array}$ & $\begin{array}{c}01(01.7 \%) \\
15(26.3 \%) \\
41(71.9 \%) \\
-\end{array}$ & $\begin{array}{c}01(01.9 \%) \\
13(25.4 \%) \\
37(72.5 \%) \\
-\end{array}$ \\
\hline $\begin{array}{l}\text { Mean days of nocturnal heartburn } \\
\text { (2 previous weeks) }\end{array}$ & 5.02 days & 4.41 days \\
\hline $\begin{array}{l}\text { Severity of nocturnal heartburn: } \\
\text { Absent } \\
\text { Mild } \\
\text { Moderate } \\
\text { Severe }\end{array}$ & $\begin{array}{l}26(45.6 \%) \\
12(21.0 \%) \\
19(33.3 \%) \\
-\end{array}$ & $\begin{array}{l}24(47.0 \%) \\
10(19.6 \%) \\
17(33.3 \%) \\
\quad-\end{array}$ \\
\hline $\begin{array}{l}\text { Smoking } \\
\text { Alcohol consumption (> } 40 \mathrm{~g} \text { ) } \\
\text { Coffee or tea consumption }\end{array}$ & $\begin{array}{l}10(17.5 \%) \\
18(31.5 \%) \\
22(38.5 \%)\end{array}$ & $\begin{array}{l}10(19.6 \%) \\
17(33.3 \%) \\
20(39.2 \%)\end{array}$ \\
\hline $\begin{array}{l}\text { Infection by H. pylori: } \\
\text { Positive } \\
\text { Negative }\end{array}$ & $\begin{array}{l}47(82.4 \%) \\
10(17.5 \%)\end{array}$ & $\begin{array}{l}42(82.3 \%) \\
09(17.6 \%)\end{array}$ \\
\hline
\end{tabular}

ITT: intent-to-treat population; PP: per protocol population; GERD: gastroesophageal reflux disease. $\left({ }^{*}\right)=\ln$ the two weeks prior to inclusion in the study. 
The duration of treatment was 2 weeks, with two visits, one at baseline and one at the end of treatment. During the first visit we obtained a detailed history of GERD, and recorded data such as weight, height, smoking habits, and alcohol, coffee or tea consumption.

During treatment, patients recorded the presence of heartburn episodes on a daily basis, indicating time and severity, in a case report form to be returned at the $2^{\text {nd }}$ visit. Heartburn severity was scored from 0 to 3 . Grade 0 : absence of heartburn. Grade I (mild heartburn): the patient suffered from heartburn not interfering with his or her routine activities or sleep. Grade II (moderate heartburn): the patient suffered from heartburn during a part of the day or night, which slightly or tolerably interfered with his or her routine activities or sleep. Grade III (severe heartburn): the patient suffered from heartburn during the day or night, which significantly interfered with his or her routine activities or sleep. At the $2^{\text {nd }}$ visit we assessed the level of satisfaction with treatment, and the symptoms referred in the case report form; we also collected the unused medication to evaluate compliance, and asked patients about potential adverse events.

For the treatment to be considered as valid to assess its efficacy, the primary endpoint had to be available (visit 2) with a correct therapeutic compliance (at least $80 \%$ ) and no use of forbidden treatments. After treatment completion (visit 2) symptoms were assessed with neither the patient nor the investigator being aware of the presence or absence of $H$. pylori infection.

Treatment efficacy was assessed in relation to the presence or absence of $H$. pylori infection, and the impact of age, sex, body mass index, smoking habit, alcohol, coffee or tea consumption, and how long the patient had suffered from GERD.

\section{Primary endpoint}

The primary endpoint to assess the efficacy of treatment was symptom control two weeks after treatment onset.

Symptoms were considered to be under control when these requisites were in place: a) heartburn was present for a maximum of one day or night, in mild form, in the last 7 days; and b) the patient answered the following question in the affirmative: "Is the medication you are receiving sufficiently controlling the symptoms of your disease?".

\section{Secondary endpoints}

Treatment efficacy during the first and second weeks. The following data were quantified: a) number of days with daytime heartburn and its severity; and b) number of days with nocturnal heartburn and its severity.

\section{Descriptions of the analytical groups}

1. Intent-to-treat (ITT) analysis population: it included all patients who received at least one dose of the experimental medication and attended the $2^{\text {nd }}$ visit.

2. Per protocol $(P P)$ analysis population: it included all patients in the ITT population with a treatment compliance over $80 \%$ who had not deviated from the protocol.

\section{Statistical analysis}

The statistical analysis compared treatment results in relation to the presence or absence of $H$. pylori infection with a subsequent evaluation of age, sex, body mass index, smoking habit, alcohol, coffee and tea consumption, and the time the patient had been suffering from disease. In order to determine the type of statistical test to be used (parametric or not) in the analysis, we tested goodness of fit with a Kolmogorov-Smirnov normal distribution test, and performed either Barlett's variance homogeneity test or Cochran's test, whichever was most restrictive.

For parametric quantitative variables we used an analysis of variance for repeated measures, associated with a t-test for paired data.

For non-parametric quantitative variables, and nonpaired data, we used a non-parametric Mann-Witney U test or Kruskal-Wallis test when necessary. For paired data we used Wilcoxon's test for repeated measures.

For nominal qualitative variables we used a Chisquare test, grouping data and applying Yates' correction when necessary.

All the analyses were performed using the SAS 8.1 program, with a $5 \%$ level of significance for all hypotheses tested.

\section{RESULTS}

1. Analysis populations: the intention to treat (ITT) and per protocol (PP) populations comprised 57 patients and 51 patients, respectively. Six patients were excluded from the ITT population due to a treatment compliance of less than $80 \%$, or for having used forbidden medication. The clinical data of these populations are shown in table II.

2. Helicobacter pylori infection: 49 patients from the total population $(81.6 \%), 47$ from the ITT population $(82.4 \%)$, and 42 from the PP population $(82.3 \%)$, had $H$. pylori infection. The infection was simultaneous in the gastric body and antrum in 45/49 (91.8\%), 43/47 (91.4\%), and $38 / 42(90.4 \%)$ patients, respectively. The populations with or without infection by $H$. pylori had no significant differences in the parameters shown in table II.

3. Symptom control (primary endpoint):

- In 35 patients from the ITT population $(61.4 \%)$ and 34 patients from the PP population (66.6\%) symptoms 
were satisfactorily controlled, with a maximum of one episode of mild heartburn in the last week.

ITT population: 27 of 35 patients $(77.1 \%)$ with controlled symptoms were $H$. pylori-positive and $8(22.8 \%)$ were negative. Symptoms were controlled in 27 of $47 \mathrm{H}$. pylori-positive patients $(57.4 \%)$, and 8 of $10 \mathrm{H}$. pylorinegative patients $(80 \%)$.

PP population: 26 of 34 patients $(76.4 \%)$ with controlled symptoms were $H$. pylori-positive and $8(23.5 \%)$ were negative. Symptoms were controlled in 26 of 42 $\mathrm{H}$. pylori-positive patients $(61.9 \%)$ and 8 of $9 \mathrm{H}$. pylorinegative patients $(88.8 \%)$.

2.42 patients from the ITT population (73.6\%) and 41 from the PP population (80.3\%) answered the question at visit 2 ("Is the medication you are receiving sufficiently controlling the symptoms of your disease?") in the affirmative. H. pylori infection was detected, respectively, in 80.9 and $80.4 \%$ of patients satisfied with their treatment.

No statistically significant differences were observed in symptom control, regardless of assessment for the presence or absence of $H$. pylori infection.

4. Evolution of symptoms in the ITT population:

- No. of days with daytime heartburn and maximum severity: in the first week of treatment 19 patients (33.3\%) had no heartburn, and $6(10.5 \%)$ had it on one day only. Thirty-two (32) patients $(56.1 \%)$ had heartburn on two or more days. Severity was mild or absent in 36 patients $(63.1 \%)$. In the second week of treatment 33 patients $(57.8 \%)$ had no heartburn and $5(8.7 \%)$ had it on one day only. Nineteen (19) patients (33.3\%) had heartburn on two or more days. Severity was mild or absent in 48 patients $(84.2 \%)$.

-No. of days with nocturnal heartburn and maximum severity: in the first week of treatment 23 patients $(40.3 \%)$ had no heartburn and $11(19.2 \%)$ only had it one night. Twenty-three (23) patients $(40.3 \%)$ had heartburn for two nights or more. Severity was mild or absent in 45 patients $(78.9 \%)$. In the second week of treatment 38 patients $(66.6 \%)$ had no heartburn, and $8(14.0 \%)$ had it only one night. Eleven (11) patients (19.2\%) had heartburn for two nights or more. Severity was mild or absent in 51 patients $(89.4 \%)$.

5. Evolution of symptoms in the PP population:

-Daytime heartburn: in the first week of treatment 18 patients $(35.2 \%)$ had no heartburn and $6(11.7 \%)$ had it on one day only. Twenty-seven (27) patients (52.9\%) had heartburn on two or more days. Severity was mild or absent in 34 patients $(66.6 \%)$. In the second week of treatment 30 patients $(58.8 \%)$ had no heartburn and $5(9.8 \%)$ had it on one day only. Sixteen (16) patients (31.3\%) had heartburn on two or more days. Severity was mild or absent in 45 patients $(88.2 \%)$.

-Nocturnal heartburn: in the first week of treatment 21 patients $(41.1 \%)$ had no heartburn and $10(19.6 \%)$ only had it one night. Twenty (20) patients (39.2\%) had heartburn for two nights or more. Severity was mild or absent in 41 patients $(80.3 \%)$. In the second week of treatment 34 patients $(66.6 \%)$ had no heartburn and 8 $(15.6 \%)$ had it on one night only. Nine (9) patients (17.6\%) had heartburn for two nights or more. Severity was mild or absent in 47 patients $(92.1 \%)$.

\section{DISCUSSION}

GERD is a heterogeneous disease in its pathogenesis and clinical presentation (1-4).

Most patients with GERD do not have erosive esophagitis, and this situation is known as GERD with negative endoscopy or non-erosive reflux disease (NERD). This condition is not considered a mild or initial presentation of GERD, at the opposite end of esophagitis or Barrett's esophagus, but as a form of GERD in its own right. Most patients with NERD remain stable over the years, and do not evolve to erosive esophagitis. Anti-secretory treatment is less effective in NERD than in erosive esophagitis, probably due to the different impact of pathogenic factors $(34,35)$. NERD is a more heterogeneous condition from a pathogenic perspective than GERD with esophagitis. A study of patients with NERD using $\mathrm{pH}$-metry shows that in $50-70 \%$ of cases there is an abnormal exposure of the esophagus to acid, and that in the remaining $30-50 \%$ the exposure to acid can be considered physiological. In these patients with functional heartburn we may see a positive $(40 \%)$ or negative $(60 \%)$ relationship between heartburn episodes and reflux. In the first case we consider the existence of a hypersensitive esophagus, and in the second case that the heartburn is provoked by non-acid stimuli. There may be a subgroup of patients with episodes of heartburn caused by minimum increases in the exposure of the esophagus to acid, even with a $\mathrm{pH}$ over 4 (1.6). This would explain the lower response to treatment with PPIs in NERD versus GERD with esophagitis, where the relation to esophageal exposure to acid is more apparent.

The relationship between infection by $H$. pylori and GERD is controversial, with contradictory data found in the literature. Some data suggest a protective or beneficial effect of $H$. pylori infection, decreasing the risk or severity of GERD. The lower prevalence of infection in more advanced levels of esophagitis, and observations regarding heartburn worsening or development after infection eradication would support this opinion. The most widespread opinion at the present time is that there is no consistent relationship between GERD and $H$. pylori infection, although an impact on certain subgroups of patients cannot be entirely ruled out (28-33).

Infection by $H$. pylori may influence GERD by altering gastric secretions and, in theory, by enhancing the effect of anti-secretory drugs. It has been considered that infection when located in the gastric antrum may favor the development of heartburn due to hypergastrinemia and gastric hypersecretion, whereas the gastric body -being diffusely affected- would cause the opposite effect. 
The influence of infection has not been detected on other factors such as gastric emptying or the function of the lower esophageal sphincter, and it is not clear whether it would affect the visceral perception of the digestive tract $(36,37)$.

NERD is a highly prevalent condition. The purpose of treatment is to control symptoms at the lowest possible dose and cost; this can be assessed either by the number of heartburn episodes and their severity, or by the patients' degree of satisfaction. In our study we assessed the efficacy of treatment considering both these parameters. Like other authors, we believe that a total absence of symptoms is not required for a treatment to be considered effective $(38,39)$. In our study we considered that treatment was effective when a maximum of one episode of mild heartburn was detected in the last week, without affecting the patient's daily activities or sleep, or when the patient was satisfied with his or her new clinical status, aspects also evaluated in other studies. Lansoprazole, at a dose of $15 \mathrm{mg} /$ day, is shown in our study to be an effective treatment in a considerable percentage of patients with NERD, with or without infection by $H$. pylori. In $66.6 \%$ of patients symptoms were controlled after two weeks of treatment according to clinical criteria as established in the protocol, and $80 \%$ of patients considered that treatment had satisfactorily controlled NERD symptoms.

During this study we observed a progressive reduction in the number of days with both daytime heartburn, absent or present only one day in $68.6 \%$ of patients, and nocturnal heartburn, absent or present only one night in $82.26 \%$ of patients in the last week of treatment. We also observed a progressive reduction in the severity of both daytime and nocturnal heartburn during treatment. These data are consistent with those provided by other studies $(16,40)$.

The study was designed as double-blind for the absence or presence of infection by $\mathrm{H}$. pylori, and exposure to this study factor was not assigned in a controlled manner. It is interesting to note the high prevalence of infection by $H$. pylori (82\%) in our group of patients with NERD without gastroduodenal peptic disease, and the fact that in most cases the infection was simultaneous in the gastric body and antrum. These circumstances make it difficult to assess the influence of $H$. pylori infection and its location in the gastric mucosa on the response to anti-secretory treatment. The prevalence of $H$. pylori infection seen in our study is greater than initially expected (approximately 50\%) and similar to that seen by Boixeda et al. in Madrid, with $74.5 \%$ in patients with GERD and esophagitis, and $76.4 \%$ in control patients with a normal endoscopy (41).

We may conclude, with the limitations inherent to a pilot study, that lansoprazole $15 \mathrm{mg} /$ day is an effective treatment for NERD. Treatment with lansoprazole $15 \mathrm{mg}$ would be an acceptable initial therapeutic strategy in NERD, a condition with a growing prevalence and a high impact on healthcare costs. In the patient sample studied we did not detect an impact of infection by $H$. pylori on response to treatment.

\section{REFERENCES}

1. Fass R. Epidemiology and pathophysiology of symptomatic gastroesophageal reflux disease. Am J Gastroenterol 2003; 98 (Supl.): S2S7.

2. Ofman JJ, The economic and quality-of-life impact of symptomatic gastroesophageal reflux disease. Am J Gastroenterol 2003; 98 (Supl.): S8-S14.

3. Buttar NS, Faik GW. Pathogenesis of gastroesophageal reflux and Barret esophagus. Mayo Clin Proc 2001; 76: 226-34.

4. Wong WM, Wong BCY. Definition and diagnosis of gastroesophageal reflux disease. J Gastroenterol Hepatol 2004; 19 (Supl. 3): S26-32.

5. Tack J, Fass R. Review article: approaches to endoscopic-negative reflux disease: part of the GERD spectrum or a unique acid-related disorder? Aliment Pharmacol Ther 2004; 19 (Supl. 1): 28-34.

6. Fass R, Tougas G. Functional heartburn: the stimulus, the pain, and the brain. Gut 2002; 51: 885-92.

7. Kahrilas PJ. Diagnostic of symptomatic gastroesophageal reflux disease. Am J Gastroenterol 2003; 98 (Supl.): S15-S23.

8. Fennerty MB, Castell D, Fendrick AM, et al. The diagnosis and treatment of gastroesophageal reflux disease in a managed care environment. Sugested disease management guidelines. Arch Intern Med 1996; 156: 477-84.

9. Hillman AL, Bloom BS, Fendrich AM, Schwartz JS. Cost and quality effects of alternative treatments for persistent gastroesophageal reflux disease. Arch Intern Med 1992; 152: 1467-72.

10. Manzionna G, Pace F, Porro B. Efficacy of lansoprazole in the shortand long-term treatment of gastro-oesophageal reflux disease. Clin Drug Invest 1997; 14: 450-6.

11. Benhaim MC, Evereux M, Salducci J, Petite JP, Lemaire M. Lansoprazole and ranitidine in treatment of reflux oesophagitis: double blind comparative trial. Gastroenterology 1990: 98: A20 (Abstract).

12. Castell Do, Ritcher JE, Robinson M, Sontang SJ, Haber MM. Efficacy and safety of lansoprazole in the treatment of erosive reflux esophagitis. Am J Gastroenterol 1996; 91: 1749-57.

13. Robinson M, Lanza F, Avner D, Haber M. Effective maintenance treatment of reflux esophagitis with low-dose lansoprazole. A randomized, double-blind, placebo-controlled trial. Ann Intern Med 1996; 124: 859-67.

14. Baldi F, Morselli-Labate AM, Cappiello R, Ghersi S; Italian Lansoprazole Study Group. Daily low-dose versus alternate day full-dose lansoprazole in the maintenance treatment of reflux esophagitis. Am J Gastroenterol 2002; 97: 1357-64.

15. Richter JE, Kovacs TOG, Greski-Rose PA, Huang B, Fisher R. Lanzoprazole in the treatment of heartburn in patients without erosive oesophagitis. Aliment Pharmacol Ther 1999; 13: 795-804.

16. Richter JE, Campbell DR, Kahrilas PJ, Huang B, Fludas C. Lansoprazole compared with ranitidine for the treatment of nonerosive gastroesophageal reflux disease. Arch Intern Med 2000; 160: 1803-9.

17. Raghunath AS, Hungin APS, Woof D, Childs S. Systematic review: The effect of Helicobacter pylori ands its eradication on gastro-oesophageal reflux disease in patients with duodenal ulcers or reflux oesophagitis. Aliment Pharmacol Ther 2004; 20: 733-44.

18. Harvey RF, Lane JA, Murray LJ, Harvey IM, Donovan JL, Nair P. Randomised controlled trial of effects of Helicobacter pylori infection and its eradication on heartburn and gastro-oesophageal reflux: Bristol Helicobacter Project. BMJ 2004; 328: 1417-9.

19. Guliter S, Kandilci U. The effect of Helicobacter pylori eradication on gastroesophageal reflux disease. J Clin Gastroenterol 2004; 38 : 750-5.

20. Beales IL. Helicobacter pylori and gastro-oesophageal reflux disease: important data were not presented. BMJ 2004; 329: 402.

21. O'Connor HJ. Review article: Helicobater pylori and gastroesophageal reflux disease. Clinical implication and manegement. Aliment Pharmacol Ther 1999; 13: 17-27. 
22. Wu JC, Sung JJ, Ng EK, et al. Prevalence and distribution of Helicobacter pylori in gastroesophageal reflux disease: a estudy from the East. Am J Gastroenterol 1999; 94: 1790-4.

23. McColl KE. Review article: Helicobacter pylori and gastroesophageal reflux disease: The European perspective. Aliment Pharmacol Ther 2004; 20 (Supl. 8): 36-9.

24. Vicari JJ, Peek RM, Falk GW, et al. The seroprevalence of cag Apositive Helicobacter pylori strains in the spectrum of gastroesophageal reflux disease. Gastroenterology 1998; 115: 50-7.

25. Fallone CA, Barkun AN, Mayrand S, et al. There is no difference in the disease severity of gastro-oesophageal reflux disease between patients infected and not infected with Helicobacter pylori. Aliment Pharmacol Ther 2004; 20: 761-8.

26. Malfertheiner P, Gerards C. Helicobacter pylori infection and gastrooesophageal reflux disease: coincidence or association? Baillieres Best Pract Res Clin Gastroenterol 2000; 14: 731-41.

27. McKoll KE. Motion-Helicobacter pylori causes or worsens GERD: arguments against the motion. Can J Gastroenterol 2002; 16: 615-7.

28. O’Morain CA, Qasim A. Motion-Helicobacter pylori worsens GERD: arguments for the motion. Can J Gastroenterol 2002; 16: 611-4.

29. Cremonini F, Di Caro S, Delgado-Aros S, et al. Meta-analysis: the relationship between Helicobacter pylori infection and gastro-oesophageal reflux disease. Aliment Pharmacol Ther 2003; 18: 279-89.

30. Garrido Serrano A, Lepe Jiménez JA, Guerrero Igea FJ, Perianes Hernández C. Helicobacter pylori and gastroesophageal reflux disease. Rev Esp Enferm Dig 2003; 95: 788-90.

31. Gisbert JP, de Pedro A, Losa C, Barreiro A, Pajares JM. Helicobacter pylori and gastroesophageal reflux disease: lack of influence of infection on twenty-four hour esophageal ph monitoring and endoscopic findings. J Clin Gastroenterol 2001; 32: 210-4.
32. Martinek J, Kuzela L, Spicak J, Vavrecka A. Review article: the clinical influence of Helicobacter pylori in effective acid suppression-implications for the treatment of gastro-oesophageal reflux disease. Aliment Pharmacol Ther 2000; 14: 979-90.

33. Sharma P, Vakil N. Review article: Helicobacter pylori and reflux disease. Aliment Pharmacol Ther 2003; 17: 297-305.

34. Quigley EMM. Factors that influence therapeutic outcomes in symptomatic gastroesophageal reflux disease. Am J Gastroenterol 2003; 98 (Supl.): S24-S30.

35. Dean BB, Gano AD, Knight K, Ofman JJ, Fass R. Effectiveness of proton pump inhibitors in nonerosive reflux disease. Clin Gastroenterol Hepatol 2004; 2: 656-64.

36. Gerards C, Leodolter A, Glasbrenner B, Malfertheiner P. H. pylori infection and visceral hypersensitivity in patients with irritable bowel syndrome. Dis Dis 2001; 19: 170-3.

37. Zarate-López N. Helicobacter pylori en la GORD: ser o no ser. Gastroenterol Hepatol (Monog) 2003; 1: 18-24.

38. Bytzer P. Goals of therapy and guidelines for treatment success in symptomatic gastroesophageal reflux disease patients. Am J Gastroenterol 2003; 98 (Supl.): S31-S39.

39. McColl E, Junghard O, Wiklund I, Revicki DA. Assessing symptoms in gastroesophageal reflux disease how well do clinicians'assessements agree with those of their patients? Am J Gastroenterol 2005; 100: 11-8.

40. Earnest DL, Dorsch E, Jones J, et al. A placebo-controlled dose -ranging study of lansoprazole in the management of reflux esophagitis. Am J Gastroenterol 1998; 93: 238-43.

41. Boixeda D, Gisbert JP, Cantón R, Álvarez Baleriola I, Gil Grande LA, Martín de Argila C. ¿Existe alguna relación entre la infección por Helicobacter pylori y la esofagitis péptica? Med Clin (Barc) 1995; 105: 774-7. 